\title{
Effect of hawthorn standardized extract on flow mediated dilation in prehypertensive and mildly hypertensive adults: a randomized, controlled cross-over trial
}

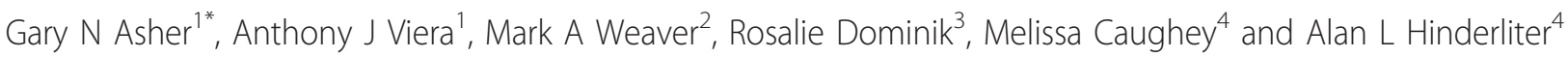

\begin{abstract}
Background: Hawthorn extract has been used for cardiovascular diseases for centuries. Recent trials have demonstrated its efficacy for the treatment of heart failure, and the results of several small trials suggest it may lower blood pressure. However, there is little published evidence to guide its dosing. The blood pressure lowering effect of hawthorn has been linked to nitric oxide-mediated vasodilation. The aim of this study was to investigate the relationship between hawthorn extract dose and brachial artery flow mediated dilation (FMD), an indirect measure of nitric oxide release.

Methods: We used a four-period cross-over design to evaluate brachial artery FMD in response to placebo or hawthorn extract (standardized to $50 \mathrm{mg}$ oligomeric procyanidin per $250 \mathrm{mg}$ extract). Randomly sequenced doses of hawthorn extract $(1000 \mathrm{mg}, 1500 \mathrm{mg}$, and $2500 \mathrm{mg}$ ) and placebo were assigned to each participant. Doses were taken twice daily for 3 1/2 days followed by FMD and a 4-day washout before proceeding to the next dosing period.
\end{abstract}

Results: Twenty-one prehypertensive or mildly hypertensive adults completed the study. There was no evidence of a dose-response effect for our main outcome (FMD percent) or any of our secondary outcomes (absolute change in brachial artery diameter and blood pressure). Most participants indicated that if given evidence that hawthorn could lower their blood pressure, they would be likely to use it either in conjunction with or instead of lifestyle modification or anti-hypertensive medications.

Conclusion: We found no evidence of a dose-response effect of hawthorn extract on FMD. If hawthorn has a blood pressure lowering effect, it is likely to be mediated via an NO-independent mechanism.

Trial Registration: This trial has been registered with ClinicalTrials.gov, a service of the U.S. National Institutes of Health: NCT01331486.

Keywords: Hawthorn, Crataegus, hypertension, prehypertension, flow mediated dilation, Phase I

\section{Background}

Hawthorn (Crataegus spp.) is a thorny shrub that grows commonly in northern temperate regions around the world. Typically the leaf and flower, berry, or a combination of all three are consumed as a powder, tea, or liquid extract. Its therapeutic use is reported as early as

\footnotetext{
*Correspondence: gasher@med.unc.edu

'Department of Family Medicine, University of North Carolina, Chapel Hill, NC, USA

Full list of author information is available at the end of the article
}

the $1^{\text {st }}$ century $\mathrm{BCE}$, and references to its use in cardiovascular diseases date to the 1600's [1].

The chemical constituents considered to be the primary bioactive components of hawthorn are the flavonoids and oligomeric procyanidins (OPCs) [2]. Hawthorn extracts have been shown to enhance release of nitric oxide (NO) from vascular endothelium causing vasodilation, which appears to be associated with the OPC-rich fraction of hawthorn extract [3-5].

\section{Biomed Central}


While traditional indications for use of hawthorn include asthma, diabetes, and neurasthenia [6], the most substantial evidence for its benefit resides in treatment of mild to moderate heart failure (HF) $[7,8]$. As an adjunct to conventional treatment in patients with $\mathrm{HF}$ (New York Heart Association classes I - III), hawthorn extract may provide additional benefit in symptom control (eg. fatigue, shortness of breath) and physiologic outcomes (eg. maximal work load tolerance, exercise tolerance, pressure-heart rate product) [8]. Several small clinical trials with hawthorn have demonstrated modest blood pressure reduction [9-11], and a few preclinical studies have shown reductions in total cholesterol, lowdensity lipoprotein, and ApoB synthesis [12-16]. However, there are no published evaluations of human doseresponse to hawthorn to guide its dosing. We sought to evaluate the dose-response effect of a hawthorn extract standardized to OPC concentration on flow-mediated dilation of the brachial artery (FMD), an indirect measure of NO release [17].

\section{Methods}

\section{Participants}

English-speaking adults aged 18 years and older with recent average ambulatory systolic blood pressure (BP) between 120-155 mm Hg and diastolic BP between 80$95 \mathrm{mmHg}$ were eligible for enrollment. People using any antihypertensive medications or tobacco products, as well as those with a prior diagnosis of diabetes mellitus, coronary artery disease, severe aortic stenosis, idiopathic hypertrophic subaortic stenosis, or upper extremity vascular obstruction were excluded. Pregnant or breastfeeding women, and women using estrogen-containing birth control methods, were also excluded. All participants were instructed to forego the use of dietary supplements such as vitamins $\mathrm{C}$ and $\mathrm{E}$, fish oil, niacin, arginine, and over-the-counter decongestants and nonsteroidal anti-inflammatory agents for the duration of the study. Participants were asked to refrain from alcohol, vigorous exercise, and use of phosphodiesterase inhibitors prior to study visits. Participants experiencing any respiratory or viral illness associated with fever, as well as any acute inflammatory conditions, were suspended from involvement in the study until the acute illness had resolved. The Institutional Review Board at the University of North Carolina approved the research protocol, and all study participants gave written consent prior to participation in the study.

\section{Study design}

We used a randomized, placebo-controlled, doubleblind, four-period crossover design. Each participant had brachial artery FMD measured at baseline and after each dosing period. Capsules containing $250 \mathrm{mg}$ of hawthorn standardized extract (HSE) and a sufficient number of matching placebo capsules were combined to create four dosage levels: placebo, $1000 \mathrm{mg}, 1500 \mathrm{mg}$, and $2500 \mathrm{mg}$. We chose two doses (ie. $1000 \mathrm{mg}$ [200 $\mathrm{mg}$ OPC], $1500 \mathrm{mg}$ [300 $\mathrm{mg} \mathrm{OPC}$ ]) to approximate the previously reported doses from heart failure trials (ie. $900 \mathrm{mg}$ [168 mg OPC], $1800 \mathrm{mg}$ [337 mg OPC]) [18-20] and a third dose (2500 $\mathrm{mg}$ [500 $\mathrm{mg}$ OPC]) above those previously tested.

Capsules were prepackaged into single-dose cups each containing five capsules that were taken twice daily (e.g., at $1500 \mathrm{mg}$, each dose cup contained 3 HSE and 2 placebo capsules). Within each period, doses were taken for three consecutive days followed by a final dose on the morning of the FMD measurement for a total of seven consecutive doses. There was a minimum $31 / 2$ day washout period between dosage levels. The washout period was timed to be greater than 5 half-lives of the hawthorn anthocyanidin epicatechin $\left(t_{1 / 2}=80 \mathrm{~min}\right)$ [21]. Four random dose sequences were created using a Williams design [22] and participants were randomly assigned to sequence following a schedule generated by an independent statistician; allocation concealment was accomplished using consecutively numbered sealed opaque envelopes. The study pharmacist opened envelopes in sequential order and dispensed the appropriate dose cups; all other study personnel were blinded until all participants completed follow-up.

HSE (Hawthorn Supreme Liquid Phyto-Caps) and matching placebo were obtained from Gaia Herbs, Inc., Brevard, NC. The extract was produced from a single, certified organic study lot grown at the Gaia Herb Farm and was processed using a standard protocol. Extraction solvents included grain alcohol and water. Approximately $1000 \mathrm{mg}$ of whole leaf and flower was used to produce a single $250 \mathrm{mg}$ capsule standardized to $50 \mathrm{mg}$ oligomeric procyanidins, which was verified using ultraviolet-visible spectroscopy. Placebo caps were matched for color and liquid viscosity.

\section{Procedures}

FMD was measured using a $12.5 \mathrm{MHz}$ imaging probe interfaced with an ATL HDI 5000 ultrasound machine. A single experienced technician performed all FMD measurements under standard conditions (i.e., participants fasted overnight, measurements were taken in the morning) [23].

Participants were asked to lie supine on a stretcher in a quiet private room, and a pneumatic tourniquet was placed around the right lower arm distal to the brachial artery. Gated baseline images of the brachial artery and Doppler flow profiles were acquired after 15 minutes of supine rest. The pneumatic cuff was then inflated to a pressure of $200 \mathrm{~mm} \mathrm{Hg}$ for 5 minutes and increased 
flow (i.e., hyperemia) induced by sudden cuff deflation. A second Doppler scan was performed immediately following deflation, with imaging of the brachial artery for 90 seconds. Digital images of the artery were stored for subsequent off-line quantification.

Doppler measurements of brachial arterial flow during imaging at baseline and during hyperemia were quantified by the HDI 500 ATL ultrasound machine. The Hi$\mathrm{Q}$ trace tracked the flow curves and quantified the velocity-time integral (VTI) and peak systolic velocity under each condition.

\section{Outcome measures}

Brachial arterial diameter (BAD) was measured from the lumen-intimal interfaces of the proximal and distal arterial walls using customized software (Brachial Tools, Medical Imaging Applications, LLC). Data from at least three consecutive end-diastolic frames were averaged for each resting baseline measurement $(R)$ and from at least three frames at maximum dilation during reactive hyperemia $(\mathrm{H})$. Change in brachial artery diameter $(\triangle \mathrm{BAD})$ and FMD \%, our primary outcome, were calculated as:

$$
\triangle \mathrm{BAD}=\mathrm{H}-\mathrm{R} ; \mathrm{FMD} \%=((\mathrm{H}-\mathrm{R}) / \mathrm{R}) \times 100 .
$$

Blood pressure (BP) was measured by trained nursing staff shortly after arrival to the study center. Measurements were performed according to recommended timing and positioning and using the appropriate BP cuff size by a validated automated office-type oscillometric device [24]. Three measurements were taken and averaged to determine the participant's office BP measurement for the visit. Ambulatory blood pressure measurements used for enrollment into the study were recorded using an Oscar 2 ambulatory BP monitor programmed to record blood pressure at 30-minute intervals from 6 am to $11 \mathrm{pm}$ and at hourly intervals during the remainder of the day.

\section{Side Effects, Adherence, and Acceptability}

Side effects and adverse events were evaluated at each weekly follow-up visit using a symptom checklist that was administered by the study coordinator. Symptom severity was self-graded as mild, moderate, or severe, and further details were elicited in free form.

Adherence to the dosing regimen was measured using participant self-report. Participants were asked to return any unused doses at their next study visit.

To evaluate how participants thought they might use hawthorn if it were proven to be effective for reducing blood pressure, we asked four questions: (1) how likely would you be to take hawthorn instead of lifestyle modification?; (2) how likely would you be to take hawthorn in conjunction with lifestyle modification?; (3) how likely would you be to take hawthorn instead of a prescription antihypertensive medication?; and (4) how likely would you be to take hawthorn in conjunction with a prescription antihypertensive medication? Answers were recorded on a 5-point likert scale from 'very likely' to 'very unlikely' with 'unsure' at the center of the scale.

\section{Analysis}

Our primary outcome was FMD \%. We tested the doseresponse effect using a modified linear contrast [25] in a mixed effects linear regression model that included random subject effects. The model included fixed effects for dose, period, resting BAD within each period, and baseline FMD \%. We first assessed the potential for carry-over effects by including dummy indicators for dose used in the prior period (all indicators were zero for the first period and for periods following placebo) and conducting a 3 degree of freedom test at the 0.05 level. If non-significant, the carry-over indicators were removed, and the modified linear contrast was tested at the 0.05 level. If a significant dose-response effect was observed, the pre-specified plan was pairwise testing of each dose, in descending order, versus placebo until a non-significant comparison was observed. Similar methods were used to assess dose-response effects on $\triangle \mathrm{BAD}$, resting $\mathrm{BAD}$, systolic and diastolic $\mathrm{BP}$, and hyperemic VTI. Given published information on the variance and covariance of repeated FMD measurements and assuming that a $2500 \mathrm{mg}$ dose would lead to a $1 \%$ increase in mean FMD levels, we calculated that obtaining complete data on at least 20 participants would provide at least $80 \%$ power to detect a dose-response relationship even if there were no effects at the lower doses [26]. All analyses were conducted in SAS, Version 9.2 (SAS Institute, Cary, NC).

\section{Results}

We enrolled 22 participants with baseline systolic/diastolic ambulatory blood pressure (ABP) between 120$155 / 80-95 \mathrm{~mm} \mathrm{Hg}$ from the University of North Carolina at Chapel Hill catchment area between July 2010 and May 2011 (Figure 1). Twenty-one participants fully completed the study and were included in the analyses. Participation was halted for one subject due to hearing loss. The mean age of participants was 51 years (range 35 - 78 years), and the mean (SD) systolic ABP was 137.6 (7.7) $\mathrm{mm} \mathrm{Hg}$ and mean (SD) diastolic ABP was 81.8 (6.3) $\mathrm{mm} \mathrm{Hg}$ (Table 1).

Flow-mediated dilation, brachial artery diameter, velocitytime integral, and blood pressure

No evidence of carry-over effects for any outcome ( $\mathrm{p} \geq$ 0.23 for all models) was observed. There was no 


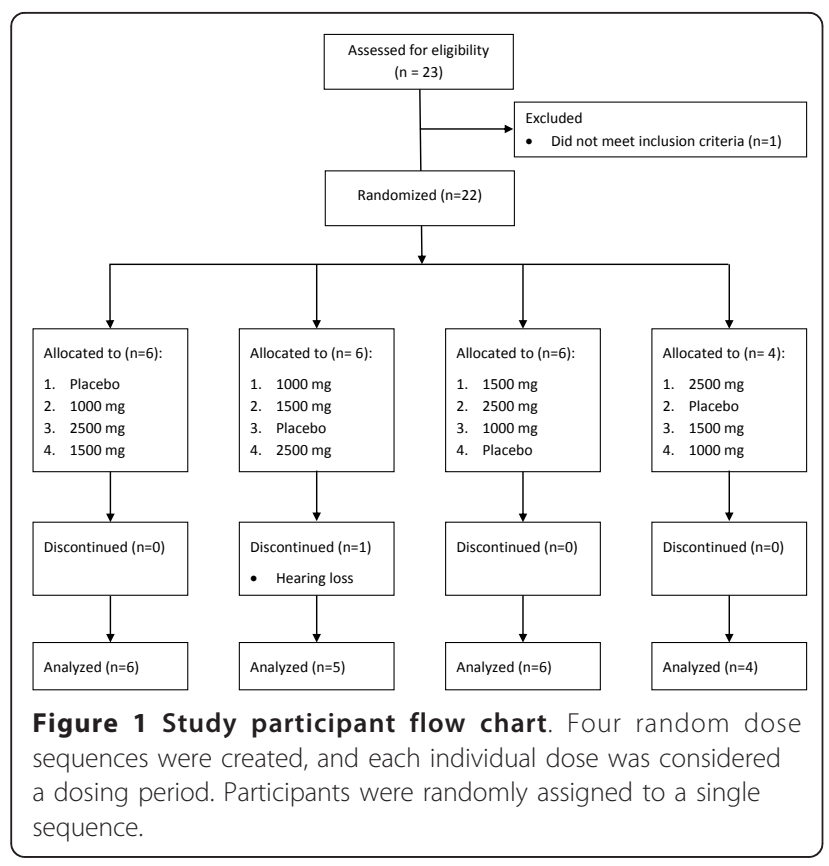

evidence of a dose-response effect for our primary outcome, FMD \% ( $\mathrm{p}=0.59)$ (Table 2). Mean change in brachial artery diameter (BAD) ranged from $0.14 \mathrm{~mm}-0.18$ $\mathrm{mm}$, with no evidence of a dose-response effect $(\mathrm{p}=$ $0.54)$. The mean $(\mathrm{SD})$ peak systolic velocity $(\mathrm{cm} / \mathrm{s})$ during hyperemia was 155.3 (22.8), with minimum and

Table 1 Baseline Characteristics $(\mathbf{N}=\mathbf{2 1})$

\begin{tabular}{ll}
\hline & Mean (SD) or $\mathbf{n}(\%)$ \\
\hline Age, years & $50.9(10.5)$ \\
\hline Amb & $29.3(5.4)$ \\
Systolic & $137.6(7.7)$ \\
Diastolic & $81.8(6.3)$ \\
\hline Baseline FMD & \\
FMD \% & $4.3(2.8)$ \\
$\triangle$ BAD, mm & $0.15(0.09)$ \\
\hline Race & $15(71.4 \%)$ \\
White & $6(28.6 \%)$ \\
Black & $9(42.8 \%)$ \\
\hline Gender & $12(57.2 \%)$ \\
Male & $10(47.7 \%)$ \\
Female & $11(52.3 \%)$ \\
\hline Marital Status & $21(100 \%)$ \\
Single & 0 \\
Married & \\
\hline Self-reported Health Status & \\
Excellent, Very Good, Good & Fair or Poor \\
\hline BMI - body mass index, BP - blood pressure, FMD - flow mediated dilation, \\
BAD - brachial artery diameter
\end{tabular}

maximum velocities of 106 and 224, respectively. There was also no evidence of a dose-response effect for resting BAD $(\mathrm{p}=0.74)$ or mean resting BAD by study period $(\mathrm{p}=0.50$, data not shown). The mean (SD) hyperemic VTI was $85.7 \mathrm{~cm}$ (19.9) with a range of 46.0 - $135.0 \mathrm{~cm}$. Among the four groups, the mean (SD) ranges of systolic and diastolic BP were 129.4 (8.1) 132.0 (10.0) mm Hg and 81.8 (7.8) - 83.0 (9.1) mm Hg, respectively, with no evidence of dose-response effects ( $\mathrm{p}=0.33$ and 0.72 , respectively).

To explore the possibility that participants with higher and lower baseline blood pressure may respond differently to HSE, we added to the primary model interactions between doses of HSE and an indicator for baseline systolic ABP either above or below the median (129 $\mathrm{mm} \mathrm{Hg}$ ). We found no evidence of an interaction $(\mathrm{p}=0.16)$.

\section{Side effects}

Side effects were uncommon and the rates of events for placebo versus HSE were typically similar. The most common side effects were mild nausea $(9.5 \%$ vs. $7.9 \%$, placebo vs. HSE), mild to moderate headache (14.3\% vs. $15.9 \%)$, and mild palpitations (4.7\% vs. $7.9 \%)$. Dizziness occurred in only a single participant taking placebo. One participant reported a fall $(2500 \mathrm{mg}$ dose) while climbing an icy staircase, and one participant reported partial hearing loss (during the $1000 \mathrm{mg}$ dose period) but had prior instances of idiopathic hearing loss.

\section{Adherence, blinding, and acceptability}

Overall, 78 of the 84 dose sheets (93\%) were returned, all of which indicated that doses had been taken twice a day as directed. When the dose sheet was forgotten, we asked participants if they had taken their pills as directed, and all participants responded affirmatively. One participant reported taking two doses on the same morning instead of split AM and PM. One unused dose cup was returned by a single participant.

To assess blinding, we asked participants to guess in which dosing period they had received placebo pills. Eleven participants guessed incorrectly, one guessed correctly, and nine did not guess (we would have expected $25 \%$ to guess correctly by chance).

Most participants answered that they were likely or very likely to use hawthorn with or instead of either lifestyle modification (91\% and $67 \%$, respectively) or prescription medication (57\% and $86 \%$, respectively) if given proof that hawthorn could lower blood pressure (Table 3).

\section{Discussion}

Hawthorn and some of its individual constituents (e.g., oligomeric procyanidins [OPC], flavonoids) have been 
Table 2 Mean flow-mediated dilation, brachial artery diameter, velocity-time integral, and blood pressure by dose ( $\mathrm{N}$ = 21)

\begin{tabular}{|c|c|c|c|c|c|}
\hline & Placebo & $1000 \mathrm{mg}$ & $1500 \mathrm{mg}$ & $2500 \mathrm{mg}$ & $p$-value ${ }^{1}$ \\
\hline \multicolumn{6}{|l|}{ FMD } \\
\hline$\triangle B A D, m m$ & $0.18(0.14)$ & $0.16(0.12)$ & $0.14(0.13)$ & $0.17(0.12)$ & 0.54 \\
\hline FMD, \% & $5.3(4.3)$ & $5.0(4.1)$ & $4.3(4.0)$ & $4.9(4.1)$ & 0.59 \\
\hline \multicolumn{6}{|l|}{ BAD, mm } \\
\hline Resting & $3.5(0.7)$ & $3.5(0.8)$ & $3.6(0.8)$ & $3.5(0.8)$ & 0.74 \\
\hline Hyperemia & $3.7(0.7)$ & $3.6(0.8)$ & $3.7(0.8)$ & $3.7(0.8)$ & - \\
\hline VTI, cm & $85.7(20.8)$ & $91.3(19.5)$ & $82.0(21.4)$ & $83.9(18.0)$ & 0.31 \\
\hline \multicolumn{6}{|c|}{ Blood Pressure, $\mathrm{mm} \mathrm{Hg}$} \\
\hline Systolic & $129.4(8.1)$ & $130.7(10.7)$ & $131.1(13.6)$ & $132.0(10.0)$ & 0.33 \\
\hline Diastolic & $82.8(7.3)$ & $81.8(7.8)$ & $83.0(9.1)$ & $82.3(7.7)$ & 0.72 \\
\hline
\end{tabular}

${ }^{1} p$-value for modified linear contrast assessing dose-response from mixed effects linear model controlling for period and baseline response. Models for FMD also controlled for resting BAD.

All values expressed as mean (SD).

FMD - flow mediated dilation, BAD - brachial artery diameter, VTI - velocity-time integral

shown to have effects on nitric oxide (NO) and endothelial function, which are implicated in hypertension and CVD $[27,28]$. Hawthorn has been shown to produce endothelial-dependent arterial vasodilation in mice, rats, pigs, and humans $[3,4,29,30]$ that is linked to activation of endothelial NO-synthase (NOS) [3]. Studies of different fractions of HSE have demonstrated that it is the OPC-rich fraction that mediates hawthorn's vasodilatory effects $[3,4]$. Therefore, we sought to investigate the effects of a standardized, OPC-concentrated hawthorn formulation on flow-mediated brachial artery dilation, a measure of NO release. However, we did not detect a dose-response effect on FMD, and no dose appeared to have an effect significantly different than placebo, indicating that HSE may not have a clinically meaningful effect on $\mathrm{NO}$ in humans.

Formation of endogenous NO is typically mediated by NOS through the oxidation of the amino acid Larginine. It is now understood that profound reduction of NO occurs with aging so that a 40 year old adult

Table 3 Likelihood to use Hawthorn for blood pressure control

How likely would you be to use Hawthorn for blood pressure lowering: $(\mathrm{N}=21)$

\begin{tabular}{|c|c|c|}
\hline & $\frac{\text { instead of: }}{\mathrm{n}(\%)}$ & $\frac{\text { in conjunction with: }}{\mathrm{n}(\%)}$ \\
\hline \multicolumn{3}{|c|}{ lifestyle modification $^{1}$} \\
\hline Likely & $14(66.6)$ & $19(90.5)$ \\
\hline Unsure & $4(19.0)$ & 0 \\
\hline Unlikely & $3(14.4)$ & $2(9.5)$ \\
\hline \multicolumn{3}{|c|}{ antihypertensive medication } \\
\hline Likely & $18(85.7)$ & $12(57.2)$ \\
\hline Unsure & $2(9.5)$ & $5(23.8)$ \\
\hline Unlikely & $1(4.8)$ & $4(19.0)$ \\
\hline
\end{tabular}

${ }^{1}$ Lifestyle modification defined as dietary and/or exercise modifications. may only produce half as much $\mathrm{NO}$ as a 20 year old [31-33]. However, strategies to increase NO production by supplementing with $\mathrm{L}$-arginine have failed to demonstrate any clinically meaningful results in human trials [34], leading to the conclusion that another pathway may need to be activated to increase NO production.

Exogenous intake of nitrate in humans is converted by commensal bacteria to nitrite, which can then be reduced to NO [35]. However, the reduction process catalyzed by nitrite reductase is particularly inefficient [36]. Zand, et al. screened over 100 botanicals and found hawthorn to have the highest nitrate reductase activity. They then tested a combination supplement that was both rich in natural nitrate (beetroot) and nitrite reductase activity (hawthorn) and found that the supplement produced sustained in vitro $\mathrm{NO}$ release with a $t_{1 / 2}$ of about 60 minutes and rapid and sustained human plasma NO levels $(\sim 1.4 \mu \mathrm{M})$ after a single dose in vivo. Steady state human plasma nitrite concentrations rose from $0.10 \mu \mathrm{M}$ to $0.28 \mu \mathrm{M}$ after taking the supplement for 30 days, which was statistically significantly greater than placebo, while plasma nitrite concentrations decreased in the placebo group. Finally, mildly hypertensive participants (systolic BP $135-160 \mathrm{~mm} \mathrm{Hg}$, $\mathrm{n}=9$ ) experienced a mean $7 \mathrm{~mm} \mathrm{Hg}$ systolic and 2.7 $\mathrm{mm} \mathrm{Hg}$ diastolic blood pressure reduction, although this was not statistically significant [35].

Given what is known about the pathways of NO production, it is possible that hawthorn alone is insufficient to have a meaningful effect on $\mathrm{NO}$ and may require addition of nitrate/nitrite to be effective in vivo. We did not measure plasma nitrate concentration in the current study; additionally, the mean age of our participants was 51 years and nearly all participants were older than 40 years, so the ability to produce NO was likely limited in 
our study population. Therefore, our study results may reflect a poor native ability to produce NO.

Studies of hawthorn to lower BP in humans suggest benefits, although only three small randomized, placebo-controlled trials have been performed [9-11]. Asgary, et al. treated mildly hypertensive adults for 16 weeks and observed mean systolic and diastolic BP reductions of $13 \mathrm{~mm} \mathrm{Hg}$ and $8 \mathrm{~mm} \mathrm{Hg}$ respectively. Walker, et al. studied both untreated mildly hypertensive patients and treated hypertensive diabetic patients for 10-16 weeks and observed systolic BP reductions of 3.6-10 $\mathrm{mm} \mathrm{Hg}$ and diastolic BP reductions of 2.6-7 $\mathrm{mm} \mathrm{Hg}$. Other studies of the effect of hawthorn on heart failure also suggest that it may have a BP lowering effect, although BP was a secondary outcome in each of those studies $[19,20]$. All hawthorn studies to lower BP have had a minimum 10 week intervention period and the German Commission E recommends a minimum of 6 weeks [37]. Even if hawthorn has no effect on NO, it is still worthwhile to investigate the effects of hawthorn on blood pressure given the results of these prior trials.

\section{Limitations}

Several limitations of this study should be considered. Although we measured adherence by self-report, poor adherence could have masked any effect of hawthorn, and we did not include a pharmacologic adherence assessment. However, no individual participants exhibited a dose-response effect, and it would be very unlikely that all participants were uniformly poorly adherent. Pharmacokinetic parameters of hawthorn constituents are poorly described for humans. Reports in rodents demonstrate poor oral absorption and bioavailability for some constituents of hawthorn [21]. Poor absorption of the HSE pills could confound our results, but would not contradict preclinical in vitro and ex vivo findings. However, similar doses of HSE have been used for trials in patients with HF that have shown beneficial effects, suggesting there is sufficient oral bioavailability of HSE to demonstrate physiologic effects. It is possible that twice daily dosing of HSE for 4 days is insufficient to have an effect on NO production. However, most mechanisms to increase NO production in response to shear stress, such as that produced during FMD, take minutes to hours to occur (eg. calcium ion flux, eNOS activation, eNOS gene transcription) [23].

Little is known about differences among HSE formulations so our results may not be generalizable to other hawthorn formulations. The extract for this trial was a whole leaf and flower formulation with sufficient plant material to provide OPC at high concentrations. Other extraction techniques may favor a different mix of constituents (ie. hydrophilic vs hydrophobic extraction processes), as would doping a low OPC extract with additional OPC-rich fraction to obtain high OPC concentrations.

\section{Conclusion}

We found no evidence that flow mediated dilation, an indirect measure of NO, is altered by multidose administration of hawthorn standardized extract. If there is a blood pressure lowering effect of hawthorn, it is likely to occur by mechanisms other than NO-mediated vasodilation.

\section{Acknowledgements}

This project was supported by award number UL1RR025747 from the National Center for Research Resources (GNA, RD, MAW) and R01-HL098604 from the National Heart, Lung, and Blood Institute (AJV). The University of North Carolina at Chapel Hill's Libraries provided support for open access publication. The design, analysis, and interpretation of the study, as well as the writing of the manuscript, are solely the responsibility of the authors.

\section{Author details}

'Department of Family Medicine, University of North Carolina, Chapel Hill, NC, USA. ${ }^{2}$ Department of Medicine, University of North Carolina, Chapel Hill, NC, USA. ${ }^{3}$ Department of Biostatistics, University of North Carolina, Chapel Hill, NC, USA. ${ }^{4}$ Division of Cardiology, University of North Carolina, Chapel Hill, NC, USA.

\section{Authors' contributions}

GNA conceived of the study, participated in its design and coordination, and drafted the manuscript. AJV participated in the design of the study and helped to draft the manuscript. MAW performed the statistical analysis and edited the manuscript. RD participated in the design of the study. MC gathered the FMD data. ALH participated in the study design and coordination, and helped draft the manuscript. All authors read and approved the final manuscript.

\section{Competing interests}

Hawthorn standardized extract and placebo capsules were generously donated by Gaia, Inc.

Received: 20 December 2011 Accepted: 29 March 2012 Published: 29 March 2012

\section{References}

1. Hawthorn Berry. In American Herbal Pharmacopoeia. Edited by: Upton R. Scotts Valley: AHP; 1999:24.

2. Chang Q, Zuo Z, Harrison F, Chow MS: Hawthorn. J Clin Pharmacol 2002, 42(6):605-612.

3. Brixius K, Willms S, Napp A, Tossios P, Ladage D, Bloch W, Mehlhorn U, Schwinger RH: Crataegus special extract WS 1442 induces an endothelium-dependent, NO-mediated vasorelaxation via eNOSphosphorylation at serine 1177. Cardiovasc Drugs Ther 2006, 20(3):177-184.

4. Kim SH, Kang KW, Kim KW, Kim ND: Procyanidins in crataegus extract evoke endothelium-dependent vasorelaxation in rat aorta. Life Sci 2000, 67(2):121-131.

5. Koch E, Chatterjee S: Crataegus extract WS 1442 enhances coronary flow in the isolated rat heart by endothelial release of nitric oxide. Naunyn Schmiedebergs Arch Pharmacol 2000, 361(Suppl):R48.

6. Ellingwood F: JU L: American Materia Medica, Therapeutics and Pharmacognosy. Evanston: Ellingwood's Therapeutist; 1915.

7. ESCOP Monographs. Stuttgart: Thieme; 22003.

8. Guo R, Pittler MH, Ernst E: Hawthorn extract for treating chronic heart failure. Cochrane Database Syst Rev 2008, , 1: CD005312.

9. Asgary S, Naderi GH, Sadeghi M, Kelishadi R, Amiri M: Antihypertensive effect of Iranian Crataegus curvisepala Lind.: a randomized, double-blind study. Drugs Exp Clin Res 2004, 30(5-6):221-225. 
10. Walker AF, Marakis G, Morris AP, Robinson PA: Promising hypotensive effect of hawthorn extract: a randomized double-blind pilot study of mild, essential hypertension. Phytother Res 2002, 16(1):48-54

11. Walker AF, Marakis G, Simpson E, Hope JL, Robinson PA, Hassanein M, Simpson HC: Hypotensive effects of hawthorn for patients with diabetes taking prescription drugs: a randomised controlled trial. Br J Gen Pract 2006, 56(527):437-443.

12. Chen JD, Wu YZ, Tao ZL, Chen ZM, Liu XP: Hawthorn (shan zha) drink and its lowering effect on blood lipid levels in humans and rats. World Rev Nutr Diet 1995, 77:147-154.

13. Rajendran S, Deepalakshmi PD, Parasakthy K, Devaraj H, Devaraj SN: Effect of tincture of Crataegus on the LDL-receptor activity of hepatic plasma membrane of rats fed an atherogenic diet. Atherosclerosis 1996, 123(12):235-241.

14. Shanthi S, Parasakthy K, Deepalakshmi PD, Devaraj SN: Hypolipidemic activity of tincture of Crataegus in rats. Indian J Biochem Biophys 1994, 31(2):143-146.

15. Shanthi S, Parasakthy K, Deepalakshmi PD, Niranjjali D: Protective effect of tincture of Crataegus on wxidative stress in experimental atherosclerosis in rats. J Clin Biochem Nutr 1996, 20:211-223.

16. Zhang Z, Ho WK, Huang $Y$, James AE, Lam LW, Chen ZY: Hawthorn fruit is hypolipidemic in rabbits fed a high cholesterol diet. J Nutr 2002, 132(1):5-10.

17. Moens AL, Goovaerts I, Claeys MJ, Vrints CJ: Flow-mediated vasodilation: a diagnostic instrument, or an experimental tool? Chest 2005, 127(6):2254-2263.

18. Tauchert M: Efficacy and safety of crataegus extract WS 1442 in comparison with placebo in patients with chronic stable New York Heart Association class-III heart failure. Am Heart J 2002, 143(5):910-915.

19. Tauchert M, Gildor A, Lipinski J: [High-dose Crataegus extract WS 1442 in the treatment of NYHA stage II heart failure]. Herz 1999, 24(6):465-474, discussion 475.

20. Weikl A, Assmus KD, Neukum-Schmidt A, Schmitz J, Zapfe G, Noh HS, Siegrist J: [Crataegus Special Extract WS 1442. Assessment of objective effectiveness in patients with heart failure (NYHA II)]. Fortschr Med 1996 114(24):291-296.

21. Chang Q, Zuo Z, Ho WK, Chow MS: Comparison of the pharmacokinetics of hawthorn phenolics in extract versus individual pure compound. $J$ Clin Pharmacol 2005, 45(1):106-112.

22. Wang B, Wang X, Gong L: The Construction of a Williams Design and Randomization in Cross-Over Clinical Trials Using SAS. Journal of Statistical Software 2009, 29, Code snippet 1, pp1-10.

23. Corretti MC, Anderson TJ, Benjamin EJ, Celermajer D, Charbonneau F, Creager MA, Deanfield J, Drexler H, Gerhard-Herman M, Herrington D, et al: Guidelines for the ultrasound assessment of endothelial-dependent flow-mediated vasodilation of the brachial artery: a report of the International Brachial Artery Reactivity Task Force. J Am Coll Cardiol 2002 39(2):257-265.

24. Pickering TG, Hall JE, Appel LJ, Falkner BE, Graves J, Hill MN, Jones DW, Kurtz T, Sheps SG, Roccella EJ: Recommendations for blood pressure measurement in humans and experimental animals: Part 1: blood pressure measurement in humans: a statement for professionals from the Subcommittee of Professional and Public Education of the American Heart Association Council on High Blood Pressure Research. Hypertension 2005, 45(1):142-161.

25. Dmitrienko A, Fritsch K, Hsu J, Ruberg S: Design and analysis of doseranging clinical studies. In Pharmaceutical Statistics Using SAS: A Practical Guide. Edited by: Dmitrienko A, Chuangstein C, Ralph D'Agostino S. Cary: SAS Institute, Inc; 2007:274-311.

26. Donald AE, Halcox JP, Charakida M, Storry C, Wallace SM, Cole TJ, Friberg P, Deanfield JE: Methodological approaches to optimize reproducibility and power in clinical studies of flow-mediated dilation. J Am Coll Cardiol 2008, 51(20):1959-1964.

27. Panza JA, Quyyumi AA, Brush JE Jr, Epstein SE: Abnormal endotheliumdependent vascular relaxation in patients with essential hypertension. $N$ Engl J Med 1990, 323(1):22-27.

28. Shimbo D, Grahame-Clarke C, Miyake Y, Rodriguez C, Sciacca R, Di Tullio M, Boden-Albala B, Sacco R, Homma S: The association between endothelial dysfunction and cardiovascular outcomes in a population-based multiethnic cohort. Atherosclerosis 2007, 192(1):197-203.
29. Chen ZY, Zhang ZS, Kwan KY, Zhu M, Ho WK, Huang Y: Endotheliumdependent relaxation induced by hawthorn extract in rat mesenteric artery. Life Sci 1998, 63(22):1983-1991

30. Vierling W, Brand N, Gaedcke F, Sensch KH, Schneider E, Scholz M: Investigation of the pharmaceutical and pharmacological equivalence of different Hawthorn extracts. Phytomedicine 2003, 10(1):8-16.

31. Egashira K, Inou T, Hirooka Y, Kai H, Sugimachi M, Suzuki S, Kuga T, Urabe Y, Takeshita A: Effects of age on endothelium-dependent vasodilation of resistance coronary artery by acetylcholine in humans. Circulation 1993, 88(1):77-81.

32. Gerhard M, Roddy MA, Creager SJ, Creager MA: Aging progressively impairs endothelium-dependent vasodilation in forearm resistance vessels of humans. Hypertension 1996, 27(4):849-853.

33. Taddei S, Virdis A, Ghiadoni L, Salvetti G, Bernini G, Magagna A, Salvetti A: Age-related reduction of NO availability and oxidative stress in humans. Hypertension 2001, 38(2):274-279.

34. Schulman SP, Becker LC, Kass DA, Champion HC, Terrin ML, Forman S, Ernst KV, Kelemen MD, Townsend SN, Capriotti A, et al: L-arginine therapy in acute myocardial infarction: the Vascular Interaction With Age in Myocardial Infarction (VINTAGE MI) randomized clinical trial. JAMA 2006, 295(1):58-64

35. Zand J, Lanza F, Garg HK, Bryan NS: All-natural nitrite and nitrate containing dietary supplement promotes nitric oxide production and reduces triglycerides in humans. Nutr Res 2011, 31(4):262-269.

36. Feelisch M, Fernandez BO, Bryan NS, Garcia-Saura MF, Bauer S, Whitlock DR, Ford PC, Janero DR, Rodriguez J, Ashrafian $\mathrm{H}$ : Tissue processing of nitrite in hypoxia: an intricate interplay of nitric oxide-generating and -scavenging systems. J Biol Chem 2008, 283(49):33927-33934

37. Blumenthal M, Goldberg A, Brinckmann J: Herbal Medicine: Expanded Commission E Monographs Newton, MA: IntegrativMedicine; 2000.

\section{Pre-publication history}

The pre-publication history for this paper can be accessed here: http://www.biomedcentral.com/1472-6882/12/26/prepub

doi: $10.1186 / 1472-6882-12-26$

Cite this article as: Asher et al:: Effect of hawthorn standardized extract on flow mediated dilation in prehypertensive and mildly hypertensive adults: a randomized, controlled cross-over trial. BMC Complementary and Alternative Medicine 2012 12:26.

\section{Submit your next manuscript to BioMed Central and take full advantage of:}

- Convenient online submission

- Thorough peer review

- No space constraints or color figure charges

- Immediate publication on acceptance

- Inclusion in PubMed, CAS, Scopus and Google Scholar

- Research which is freely available for redistribution

Submit your manuscript at www.biomedcentral.com/submit
C) Biomed Central 